\title{
HLA-G: Su importancia inmunológica
}

\author{
Verónica Rincón', Edwin Manrique ${ }^{2}$ \\ ${ }^{1}$ Docente Investigador. Instituto de Virología, Universidad El Bosque. Bogotá, Colombia. \\ ${ }^{2}$ Docente Catedrático. Universidad Colegio Mayor de Cundinamarca. \\ Correspondencia: egmanrriquep@unal.edu.co
}

\begin{abstract}
Resumen
HLA-G es una molécula clase I no clásica ( $\mathrm{Ib}$ ) del Complejo Mayor de Histocompatibilidad Humano $(\mathrm{CMH})$, adopta siete isoformas, resultado del empalme alternativo de un mismo RNA inmaduro, cuatro se encuentran ligadas a la membrana (HLA-G1,-G2, -G3, -G4) y las otras tres formas son solubles (HLA-G5, G6, -G7), teniendo en común el dominio extracelular $\alpha 1$. Se expresa de forma selectiva en la interfase materno fetal desempeñando un papel crucial en la inducción de un estado de tolerancia del feto semialogénico por el sistema inmune materno. Está molécula inhibe la citólisis de las NK mediante la interacción con uno o varios receptores inhibidores presentes en las NK (KIR), presenta un limitado polimorfismo, se han descrito 15 alelos, 14 de los cuales asignados por la nomenclatura del HLA. El HLA-G está asociado con algunas patologías en la gestación, tales como las infecciones intrauterinas; pre-eclampsia y en aborto recurrente espontáneo. Los estudios van dirigidos a controlar mejor las interacciones HLA-G/células NK en la inducción de un estado de tolerancia inmunitaria en el campo del transplante y la inmunología de los tumores.
\end{abstract}

Palabras claves: HLA-G, polimorfismo, isoformas, tolerancia inmunitaria.

\section{Introducción}

El embarazo ha sido considerado a lo largo del tiempo como una paradoja inmunológica (1), dado que el feto posee hasta un $50 \%$ de información genética proveniente del padre, expresando aloantígenos paternos durante la gestación los cuales serían susceptibles de reconocimiento y rechazo por parte del sistema inmune materno. Para la madre el feto representa algo parecido a un trasplante y, por tanto, se le considera como un semialoinjerto. Se han estudiado los mecanismos potenciales durante el embarazo para prevenir la respuesta aloinmune materna, muchos de estos podrían ocurrir en la interfase materno-fetal, hoy se reconoce que uno de los más importantes corresponde al HLA-G.

HLA-G es una molécula del complejo mayor de histocompatibilidad humano (MHC) clase I no clásico (también llamados $\mathrm{I} \beta$ ), que a diferencia de los antígenos HLA clase I clásicos tiene un limitado polimorfismo siendo casi monomórfica, presenta una limitada distribución en los tejidos, expresándose selectivamente por las células del citotrofoblasto velloso en la interfase materno-fetal (2).

El locus del HLA-G, fue descrito por primera vez por Geraghty en 1987, denominándolo inicialmente como HLA-6.0. Este se identifico durante una investigación de genes similares de la clase I $\alpha$. Para ello, clonaron el DNA genómico que codificaba para un gen clase I (que no codificaba para HLA-A, -B y -C) localizado en el fragmento de restricción de $6.0 \mathrm{~kb}$, generado por la enzima Hind-III. Este gen, tenía homología con el HLA-A y -B, excepto en la ausencia del exón 7, con un codón de terminación en la región citoplasmática en el exón $6(3,4,5)$. El HLA-G se localizó en la región 


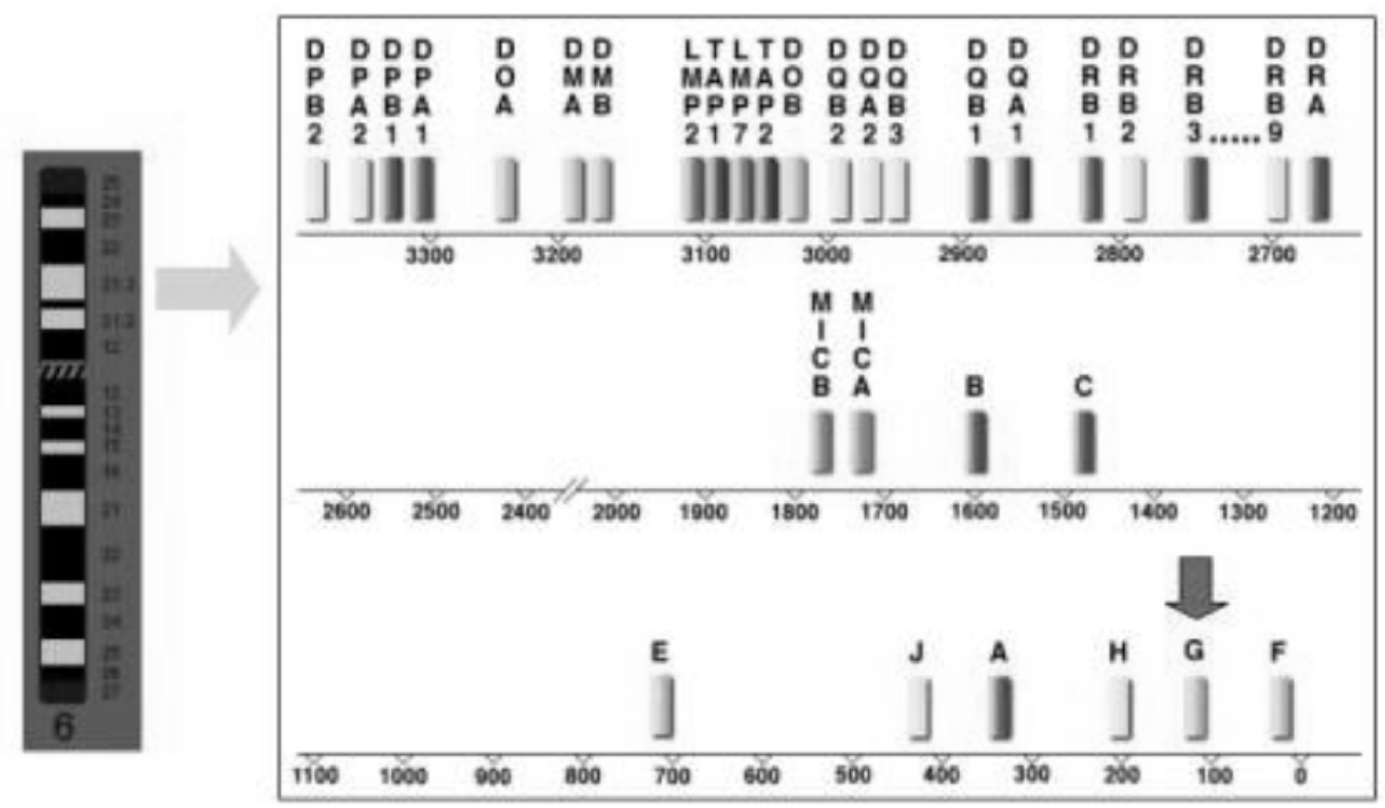

Figura 1. Mapa del Complejo Mayor de Histocompatibilidad en la región cromosómica 6p21.3. La flecha en gris señala al HLA-G (8,9).

telomérica 6p21.3, muy cerca al locus del HLA-A(6), Figura 1.

Las moléculas clase I y clase II juegan un papel importante en la inducción de una respuesta inmune específica por la presentación de péptidos antigénicos a las células T. En contraste, el HLA-G se ha identificado como una molécula implicada en la tolerancia inmune (7-9) y su principal función es proteger al aloinjerto fetal del ataque de los linfocitos $\mathrm{T}$ citotóxicos e inhibir la citólisis mediada por las células NK, en la interfase materno-fetal (10).

En esta revisión se consideran algunos de los datos más recientes publicados en cuanto a la estructura, patrón de expresión en diferentes tejidos, polimorfismo, asociación con diferentes patologías y funciones potenciales del HLA-G en el control de estas interacciones que permitirán introducir nuevos enfoques terapéuticos en el campo de los trasplantes y en la inmunología de tumores.

\section{Polimorfismo del HLA-G}

En contraste con el extensivo polimorfismo de los genes clase I clásicos del HLA, se ha considerado bajo el grado de polimorfismo en el locus del HLA-G, presentando una limitada heterogeneidad de secuencias y con pocos alelos descritos (6,11-18).

Quince alelos del HLA-G se han reportado, 14 de los cuales se asignados por la nomenclatura del HLA (13). El primer alelo descrito por Geraghty el G*01011 (salvaje), es predominante en casi todas las poblaciones, con una frecuencia variable de un $32 \%$ en poblaciones Alemanas / croatas en contraste a un $83 \%$ en poblaciones de Ghana. El alelo HLA-G*01011, no involucra sustituciones en la secuencia de aminoácidos en comparación a otros alelos: como el alelo $\mathrm{G}^{*} 0103$ (Thr31Ser), G*0102 (Gln54Arg), G*01013 (Phe241Ser), G*0141, G*0142 y G*01043 (Leu110Iso) (11).

El G*0105N es el primer alelo nulo del HLA-G descrito, presenta una deleción de una citosina (1597 del C) en la tercera base del codón 129 o en la primera base del codón 130, esto causa un cambio estructural que altera la secuencia de aminoácidos en el exón 3 (dominio $\alpha 2$ ) y genera un codón de parada prematuro en el exón 4. El HLA-G*0105N se encontró en una variedad de grupos étnicos con una frecuencia de $11,1 \%$ en poblaciones Africanas a un $0,6 \%$ en poblaciones Danesas. No ha sido encontrado en poblaciones 
caucásicas Americanas o Japonesas $(11,13)$. La descripción de individuos sanos homocigotos para el alelo $\mathrm{G}^{*} 0105 \mathrm{~N}$ indica que el HLA-G1 no es necesario para la supervivencia fetal $(14,15)$.

Sin embargo, Van der Ven y Ober en 1997 demostraron por análisis de secuencias en el exón 2 y 3 un extensivo polimorfismo del locus HLA-G en mujeres africanas no emparentadas $(12,16)$. Mediante SSCPPCR y secuenciación, se observó un alto polimorfismo en la región codificante en 18 individuos no relacionados CEPH (Centre d'Etude du polymorphisme Human) $\mathrm{y}$ tres familias de referencia del CEPH, encontrándose segregación de los alelos del HLA-G en la descendencia en heterocigotos. Está segregación fue igual a la que se presenta para el haplotipo HLA clase I, aún en la descendencia de HLA-B/C recombinante $(12,17)$.

Matte y colaboradores en el 2000 reportaron en 108 mujeres africanas no relacionadas del proyecto ZVITAMBO una frecuencia de un 39.3\% para el alelo HLA-G*01011 el más predominante en la población de estudio, seguido por el alelo $\mathrm{G}^{*} 01041$ (20,4\%), con una frecuencias similar a la reportada en Japoneses (38\%) y poblaciones Hutterite (20\%), y se encontró el alelo nulo $\mathrm{G}^{*} 0105 \mathrm{~N}$ con una frecuencia relativamente alta de $11.1 \%$ en está población que históricamente posee una gran cantidad de patógenos, lo que hace especular que la reducción en la expresión del HLA-G podría estar asociada con un aumento en el número de células T uterinas maternas, siendo benéfico en infecciones intrauterinas (13).

\section{Isoformas del HLA-G}

La secuencia y estructura del gen de HLA-G tiene gran homología con los genes HLA clase I clásicos, tiene ocho exones, siete intrones y la región 3'UTR. El exón 1 (73 pb), el exón 2 (270pb), el exón 3 (276 pb), el exón 4 (276 pb), el exón 5 (114 pb), los exones 6-8 (105 pb) codifican para el dominio $\alpha 1$, $\alpha 2, \alpha 3$, la región transmembranal y para el dominio citoplasmático respectivamente. Sin embargo, presenta un codón de parada en el exón 6 que difiere con los genes HLA clase I clásicos $(1,3,12)$. El gen del HLA$\mathrm{G}$ adopta siete formas proteicas o isoformas, resultado de empalme alternativo de un mismo RNA precursor, cuatro ligadas a la membrana (HLA-G1,-G2, -G3,-G4) y las otras tres son isoformas solubles (HLAG5, -G6,-G7) (11,19). E1 HLA-G1 presenta los dominios a1, a2, y a3 (asociado con la $b_{2}$ microglobulina) que codifican para el dominio extracelular, unidos al dominio transmembranal y un codón de parada en el exón 6 , teniendo una estructura similar a los antígenos clase I clásicos. Los transcritos HLA-G2, -G3, -G4, no incluyen el exón 3 , exón 3 y 4, o el exón 4 , respectivamente generando las isoformas truncadas. La isoforma $-\mathrm{G} 3$ sólo presenta el dominio a1, $-\mathrm{G} 2$ el dominio a1 y a3, y - G4 el dominio a1 y a2, tienen en común la región transmembranal(19-21). Los mecanismos inusuales para generar las proteínas solubles alternas del HLA-G incluyen un codón de parada en el intrón 4 para las isoformas -G5 y -G6 (22) mientras que $-\mathrm{G} 7$ presenta un codón de parada en el intrón 2. La molécula soluble completa HLA-G5 contiene el péptido líder, los dominios a1, a2, a3 y excluye el dominio transmembranal. La isoforma truncada HLAG6 no tiene el dominio a2 y excluye el dominio transmembranal, mientras que $-\mathrm{G} 7$ sólo contiene el dominio a1 (19) (Figura 2).

Todas las isoformas del HLA-G, ligadas a membrana y solubles, tienen en común el dominio a1 de la región extracelular (23), permitiéndoles mediar la protección de las células T y NK mediante citólisis. Los diferentes transcritos se encuentran en varios tipos celulares pero son más abundantes en tejidos placentarios, y en líneas celulares de coriocarcinoma derivadas de la placenta (JEG-3). Se ha encontrado expresión de HLA-G en leucocitos, especialmente en macrófagos, células epiteliales tímicas, en la cámara anterior del ojo, así como en varios tipos de tumores y células de estroma durante condiciones de inflamación y malignidad (10). La presencia de moléculas solubles en plasma y líquido amniótico (24), en biopsias de tumores (25) y suero de pacientes trasplantados (26) podrían 

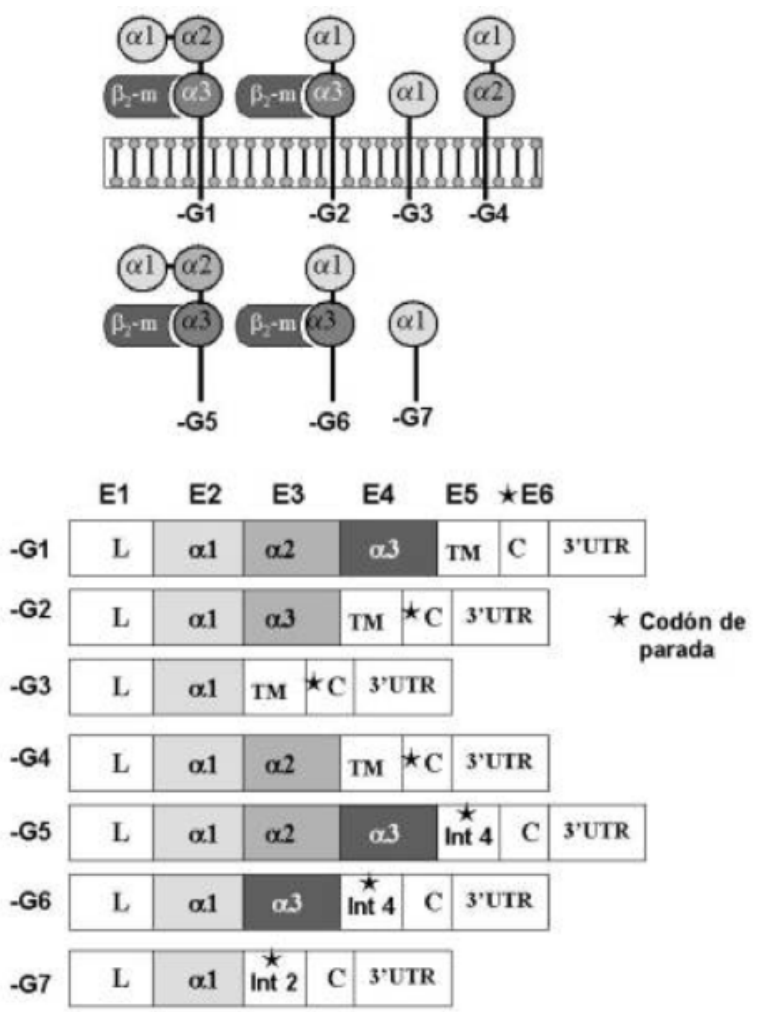

Figura 2. Representación esquemática de las isoformas del HLA-G. L: Secuencia Líder; a1, a2, a3: dominios externos; TM: dominio transmembranal; C: Dominio citoplasmático; 3'UTR: Región 3' no traducida; Int 4: intrón cuatro. La estrella indica los codones de parada.

implicar que estas isoformas actúan como mediadores de la tolerancia inmune durante el embarazo, la progresión de tumores y trasplantes $(11,27)$. Los estudios aún no son muy detallados debido a la falta de información en cuanto a la especificidad de muchos anticuerpos anti-HLA-G que se han producido (10).

\section{Funciones del HLA-G}

\section{Interacciones del HLA-G con las NK:}

Moretta y colaboradores en 1994 demostraron que la actividad de las NK pueden regularse por antígenos HLA clase I: algunos alelos HLA-C y -B presentes en células blanco actuando como moléculas protectoras contra la lisis de las NK y constituyen ligandos específicos para los receptores de las células NK $(11-12,22)$.

El HLA-G inhibe la citólisis de las NK por dos vías principalmente liberando señales inhibitorias a las NK. La primera, una vía directa, a través de la interacción con los receptores inhibitorios de las $\mathrm{Na}$ tural Killer (KIRs), incluyendo ILT2/LIR1 (presente en células NK, células mielomonocíticas, linfocitos T y B), ILT4/LIR2 (selectivamente expresado en monocitos, macrófagos y células dendríticas), p49 (presente en células NK deciduales) y KIR2DL4 (expresado en NK y linfocitos T) actuando directamente con el HLA-G. Sin embargo, ILT2, ILT4, p49 pueden interactuar con otras moléculas clase I del HLA $(11,18,28)$, Tabla 2.

El segundo mecanismo, una vía indirecta, consiste en la interacción con el receptor CD94/NKG2 (miembro de la superfamilia de las lectina C) del HLA-E (expresado en la superficie de las NK) que contiene un péptido líder derivado del HLA-G inhibiendo así la

Tabla 2. Receptores de las NK que interactúan con el HLA-G

\begin{tabular}{|c|l|l|}
\hline $\begin{array}{c}\text { Receptores de } \\
\text { reconocimiento } \\
\text { del HLA-G }\end{array}$ & Expresión celular & $\begin{array}{c}\text { Otros ligandos de HLA } \\
\text { clase I }\end{array}$ \\
\hline LIR-1/ILT2 & $\begin{array}{l}\text { Células NK, } \\
\text { subpoblaciones de } \\
\text { células T, células B, } \\
\text { células } \\
\text { mielomonociticas. }\end{array}$ & $\begin{array}{l}\text { HLA-A, -B (Bw4, Bw6) } \\
\text { clase UL18 }\end{array}$ \\
ILT4 & $\begin{array}{l}\text { Células } \\
\text { mielomonocíticas, } \\
\text { monocitos, } \\
\text { macrófagos de } \\
\text { células dendríticas. }\end{array}$ & HLA-A3, -B46, -B7 \\
& $\begin{array}{l}\text { NK, fracción de KIR+ } \\
\text { células T }\end{array}$ & \\
\hline
\end{tabular}


actividad de las NK. El HLA-E está involucrado en la regulación positiva y negativa de citotoxicidad de las NK $(11,28,29)$.

Rouas-Freiss y colaboradores encontraron que la transfección de las isoformas truncadas HLA-G2, G3 y-G4 pueden inhibir la actividad lítica de las NK, esto podría ser muy importante durante los procesos patológicos y fisiológicos en los cuales las expresión del HLA-G1 se encuentre alterada $(15,23)$.

\section{Interacciones del HLA-G con las células T:}

Le Gal y colaboradores fueron los primeros que mostraron que el HLA-G inhibe los linfocitos $\mathrm{T}$ citotóxicos (30). Esta molécula inhibe la proliferación de la respuesta de las células $\mathrm{T}$ durante la reacción primaria alogénica. Además, la diferenciación de las células $\mathrm{T}$ pueden reconocer y unirse al HLA-G, de este modo, es posible que pueda servir como un factor de reconocimiento y activación por las células $\mathrm{CD}^{+}$, actuando como supresor citotóxico de las células T(10-11).

Recientemente, se demostró que el HLA-G5 puede ser blanco en la apoptosis in vitro de las células CD8 ${ }^{+}$ activas por interacción con la molécula CD8, además, se encontró un aumento de la expresión de CD95L en $\mathrm{CD} 8{ }^{+} \mathrm{CTL}$, por tanto, la apoptosis puede ser consecuencia de la interacción CD95/CD95L. E1 HLA-G5 es principalmente expresado en la placenta, y puede tener otras funciones como la de contribuir a la eliminación de $\mathrm{CD}^{+}$aloreactivos maternos de las células $\mathrm{T}$ in vivo en la interfase materno fetal a través de la vía CD95/CD95L. La modulación de la respuesta de las células T por el HLA-G podría ser importante en el rechazo de transplantes, debido a que es mediado principalmente por los linfocitos T (10-11,31).

\section{HLA-G en el embarazo:}

Las células de trofoblasto humano son únicas en comparación con otros tejidos somáticos, ya que, no expresan las moléculas clase HLA-A y HLA-B, sólo se expresa el HLA-G (27,32). Por tanto, el HLA-G cumple un papel crucial en la tolerancia inmunitaria feto-materna, dado que, se expresa desde los primeros días siguiente a la fecundación desde el momento en que el óvulo se implanta en la pared uterina $(22,27)$.

La expresión del HLA-G en el trofoblasto durante el embarazo, sugiere un rol en la protección del feto semialogénico contra la lisis de las NK maternas y la respuesta de los linfocitos T alo-citotóxicos $(11,32)$.

Tanto el mRNA como el sus isoformas se expresan en embarazos ectópicos, en molas hidatidiformes completas y parciales. Este patrón de expresión del HLA-G en los trofoblastos no es afectado por la composición cromosómica del feto, y ello sugiere que la expresión del HLA-G es independiente del desarrollo embrionario $(33,34)$. Además, HLA-G está asociado con algunas complicaciones en la gestación, tales como las infecciones intrauterinas, en pre-eclampsia y en aborto recurrente espontáneo.

Estudios de patologías gestacionales han presentado patrones de expresión alterados del HLA-G en el trofoblasto, con un déficit de la proteína en pacientes con pre-eclampsia (37), además se ha encontrado la ausencia o reducción de la expresión del HLA-G mediante hibridización in situ (38).

HLA-G es un componente clave en los procesos de invasión del trofoblasto, en la pre-eclampsia presenta baja invasión del trofoblasto resultando en la inadecuada remodelación de los vasos sanguíneos uterinos y perfusión de la placenta (36). O'Brien en el 2001, analizó la expresión del HLA-G en 10 placentas normales, en una placenta con PIH (hipertensión inducida por el embarazo) y 6 placentas con pre-eclampsia leve realizando la comparación con líneas celulares de coriocarcinoma JEG-3 por RT-PCR y Southern. Cuando se realizó la amplificación de los exones 2,5 y 6 se observaron 3 bandas bien definidas que corresponden a las isoformas HLA-G5/HLA-G1, HLA-G2/HLA-G4 (misma longitud) y HLA-G3. La isoforma HLA-G3 se encontró ausente en casi todas las muestras de preeclampsia leve, indicando mecanismos alterados en la transcripción del HLA-G asociados con la enfermedad. 
El análisis de la distribución de los alelos usando los polimorfismos $\mathrm{C} / \mathrm{T} / 93 \mathrm{y} \mathrm{I} / \mathrm{D}-14 \mathrm{pb}$, fue significativamente diferente entre las muestra control y las muestras de pre-eclampsia, estas reflejaron un exceso de formas TI ( $\mathrm{G}^{*} 01012, \mathrm{G}^{*} 0105 \mathrm{~N}$ o $\left.\mathrm{G}^{*} 0106\right)$ en muestras de preeclampsia, en contraste a un exceso del haplotipo C-D en las muestras control (35).

Por tanto es de gran interés estudiar los genotipos del HLA-G y los patrones de expresión en pacientes con embarazos anormales, como un abordaje alternativo para dilucidar el rol del HLA-G en el embarazo.

Otra de las complicaciones asociada con el HLA-G es el aborto, uno de los desordenes más comunes del embarazo. Es de resaltar que hay pocos estudios de HLA-G y aborto, los estudios disponibles incluyen análisis genéticos incompletos, con muestras pequeñas cada uno con menos de 40 parejas con aborto recurrente $(39,40,41)$ que dificultan obtener conclusiones.

Pfeiffer y colaboradores en el 2001 encontraron un aumento de la frecuencia de los alelos del HLA$\mathrm{G}^{*} 01013$ y HLA-G*0105N en 78 parejas con aborto recurrente y en comparación con 52 controles (42).

Aldrich y colaboradores en el 2001 reportaron una asociación para los alelos HLA-G*0104 y HLA$\mathrm{G}^{*} 0105 \mathrm{~N}$ con aborto recurrente no explicado en estas parejas con etiologías genéticas específicas. La presencia del alelo $* 0105 \mathrm{~N}$ fue un dato inesperado debido a que esta población es predominantemente caucásica y este alelo se encuentra ausente en descendientes europeos, además, es común en poblaciones africanas, estos resultados indican que este alelo es un factor de riesgo para el aborto recurrente. Además, el alelo *0104 también confiere un tipo riesgo para esta complicación, la presencia de estos dos alelos no se relacionó con la eficacia del tratamiento con células mononucleares de sangre periférica. La frecuencia de estos dos alelos fue más alta en 35 parejas con una historia clínica de 5 o más abortos en comparación con 78 parejas con 2 - 3 abortos. Aunque la función de las diferentes isoformas en el embarazo aún se ha entendido a profundidad, este estudio sugiere que el HLA-G1 cumple un papel importante en el establecimiento y mantenimiento de la unidad feto-placentaria en el inicio del embarazo, por tanto, se hace necesario realizar más estudios de este tipo para entender los mecanismos por los cuales el HLA-G1 media el éxito en el embarazo (43).

\section{HLA-G y su asociación con ciertas patologías:}

\section{Expresión de HLA-G en tumores}

Los antígenos clase I del CMH juegan un papel esencial en el reconocimiento de células malignas por el sistema inmune. Estos permiten el reconocimiento de las células tumorales por las células efectoras, células NK y $\mathrm{T}$, que frecuentemente infiltran en el sitio del tumor. Las células tumorales han desarrollado estrategias para evadir la detección y eliminación por las células efectoras inmunes. El HLA-G podría favorecer a las células para el escape de la inmunovigilancia.

Los estudios de Pascale y colaboradores permitieron detectar las isoformas del HLA-G en células tumorales con altos niveles de transcripción y expresión en biopsias obtenidas de melanoma primario y metastático (44). Además, la transcripción ectópica en células tumorales y la expresión de la proteína se detectó en células de melanoma ex vivo. HLA-G confiere la habilidad para inhibir la citólisis de las NK in vitro en las líneas celulares de melanoma $(25,44)$. Varios mecanismos pueden ser considerados para que las células de melanoma escapen a la destrucción inmune, incluyendo baja-regulación de moléculas clase I del CMH, expresión de FasL y secreción de factores inhibitorios tales como la IL10. Estos resultados son importantes, debido al impacto de la expresión del HLA-G en la inhibición, tanto en las NK como en CTL responsables de atacar tumores, constituyen un nuevo parámetro en el diseño de métodos terapéuticos dirigidos a la respuesta inmune antitumoral en el 
tratamiento de melanoma humano siendo una herramienta farmacéutica de gran interés $(7,44)$.

La proteína del HLA-G se detecto tanto en macrófagos y en células dendríticas infiltrantes de carcinoma de pulmón. A su vez, se detectaron diferentes niveles de transcritos del HLA-G asociados con la falta de expresión de la proteína de HLA-G en colón, páncreas, carcinoma de vejiga y seno, así como en melanoma y líneas celulares tumorales hematopoyéticas (7).

\section{Trasplantes}

La comprensión de los mecanismos de tolerancia del sistema inmune materno hacia el semialoinjerto fetal están dirigidos al avance en el campo de los trasplantes. Se conoce que el HLA-G presenta funciones de inmunotolerancia y modulación en su expresión.

Lila y colaboradores reportaron que el HLA-G se detectó en pacientes que sufrieron trasplante de corazón y el número de rechazo agudo fue más bajo en pacientes con expresión negativa. La expresión puede contribuir a la aceptación del transplante por inhibición de la lisis mediada por las NK y linfocitos T citotóxicos, y a su vez por la supresión de la respuesta alogénica proliferativa $(11,26)$.

\section{Infecciones Virales}

La expresión del HLA-G se extiende a otros tejidos en diferentes condiciones, como durante las infecciones virales. Onno y colaboradores demostraron que los antígenos del HLA-G son producidos durante la reactivación vírica en macrófagos generados después de la estimulación alogénica de HCMV (citomegalovirus humano) latente de monocitos de sangre periférica infectados, estos datos sugieren que la inducción de las moléculas del HLA-G podría ser un mecanismo adicional que ayuda al HCMV a subvertir las defensas del huésped. Además, la expresión del HLA-E en la superficie es sobrerregulado por la secuencia líder del glicoproteína UL40 del HCMV, el cual protege de la lisis de las NK. In vivo la secreción de las moléculas del HLA-G inmunosuprimidas podrían favorecer la diseminación del virus y exacerbar la severidad de las enfermedades HCMV $(11,45)$.

\section{En inflamación}

En los procesos inflamatorios la expresión del HLA-G se reportó en enfermedades cutáneas y psoriasis. Además, el HLA-G se expresa en fibras musculares en varias miopatías inflamatorias. Además, el interferón g induce expresión en la superficie y sobrerregula los transcritos mRNA correspondientes a las diferentes isoformas del HLA-G (11).

\section{Apoptosis y HLA-G}

La muerte celular programada o apoptosis es un proceso muy común en los linfocitos y células inmunitarias en su maduración, y aún maduras este mecanismo es muy importante para regular su función. En la interrelación de los tejidos maternos con los del feto durante el embarazo, se presenta de manera reciproca una migración celular limitada. Este trafico tiene como característica intercambio de células hematopoyéticas activadas entre la sangre materna y los tejidos fetales (46). El ligando de Fas (FasL) un miembro de la familia génica del Factor de Necrosis Tumoral (TNF), restringe esta migración induciendo apoptosis mediado por antígenos de los dominios $\alpha 1$ y $\alpha 2$ de HLA-G soluble, el blanco son los linfocitos T CD8(+) y la células NK a través de los receptores celulares de los linfocitos T (TCR). Esta interacción provoca la fosforilación de p561ck una proteína tirosina cinasa (PTK) asociada con un dominio citoplasmático $\mathrm{CD} 8$, esto acarrea la translocación nuclear de NF-kB que estimula a la transcripción de ARNm de FasL, el cual desencadena la señal de muerte (46-48).

\section{Perspectivas}

Aún falta por indagar acerca de la expresión, regulación y funciones del locus del HLA-G debido, en 
NOVA - PUBLICACIÓN CIENTÍFICA ISSN:1794-2470 VOL.4 No. 5 ENERO - JUNIO DE 2006:1-116

gran parte, a la complejidad inherente de la biología que incluye la ausencia de un modelo animal, la falta de anticuerpos que detecten las diferentes isoformas del HLA-G dificultando la caracterización y patrón de expresión diferencial y además la co-expresión del HLA-C y HLA-E.

El HLA-G es el mejor mecanismo para el establecimiento de un apropiado estado inmunológico del embarazo semialogénico. Posiblemente, sus funciones potenciales podrían ser útiles en el mejoramiento no sólo de la fertilidad y el mantenimiento del embarazo, sino también del transplante de órganos, ciertamente un mejor entendimiento de la producción del HLA-G en tumores y células del estroma tumorales, así como las implicaciones funcionales de su expresión, podrían dirigir estudios en la terapia tumoral (10).

Más allá de los conocimientos fundamentales sobre las funciones de tolerancia del HLA-G, los trabajos van dirigidos a controlar las interacciones con células NK en la inducción de un estado de tolerancia inmunitaria y así hallar los medios de modular la expresión del HLA-G con el fin de crear o no un estado de tolerancia. En efecto, en el marco de los xenotransplantes, podría pensarse en inducir la expresión del HLA-G en el órgano a trasplantar para así limitar el fenómeno de rechazo. Por otra parte, ciertas células tumorales expresan el HLA-G, lo que, probablemente, permite a estos tumores escapar a la vigilancia del sistema inmunitario. Disminuyendo la expresión del HLA-G con hormonas o anticuerpos, se podría favorecer la respuesta antitumoral y limitar la proliferación maligna (27).

\section{Referencias}

1. Ober, C. HLA and pregnancy: The paradox of the allograft. Am J Hum Genet 1998; 62: 1-5.

2. Kovats S, Main EK, Librach C, Stubblebine M, Fisher SJ, DeMars R. A class I antigen, HLA-G, expressed in human trophoblast. Science 1990; 248: 220-3.

3. Geraghty DE, Koller BH, Orr HT. A Human Mayor Histocompatibility Complex class I gene that encodes a protein with a shortened cytoplasmatic segment. Proc Natl Acad Sci USA 1987; 84: 9145-9149.

4. Shukla M, Swaroop A, Srivastava R, Weissman S. The mRNA of a human class I gene HLA-G/HLA-6.0 exhibits a restricted pattern of expression. Nucleic Acids Res 1990; 18: 2189.

5. Mandelboim O, Pazmany L, Davis DM, Vales-Gomez M, Reyburn H, Rybalov B, Strominger JL. Multiple receptors for HLA-G on human natural killer cells. Proc. Natl. Acad. Sci. USA 1997; 94: 14666-14670.

6. Le Bouteiller P and Mallet V. HLA-G and pregnancy. Rev Reprod 1997; 2:7-13.

7. Carosella ED, Rouas-Freiss N, Pascale P, Dausset J. HLA-G: a tolerance molecule from the Mayor Histocompatibility Complex. Immunology Today 1999; 20: 60-62.

8. HLA Class I and II Sequence Alignments. January 2002 update. www.anthonynolan.org.uk/H16/seg/info.html.

9. Hugo Chromosome 6. Disease Loci and Genes www.abd.org/ hugo/chr6.

10. Hunt J, Petroff M, Morales P, Sedmayr P, Geraghty DE, Ober C. HLA-G in reproduction: Studies on the maternal- fetal interface. Hum Immunol 2000; 61: 1113-117.

11. Torres MI, Moreau P, Rouas-Freiss N, Dausset J, Carosella ED. HLA-G today. Inmunología 2001; 20: 18-29.

12. Carosella ED, Dausset J, Kirszenbaum M. HLA-G revisited. Immunology Today 1996; 17: 407-409.

13. Matte C, Lacaille J, Zijenah L, Ward B. The ZVITAMBO Study Group, and Roger M. HLA-G and HLA-E polymorphisms in an indigenous African population. Hum Immunol 2000; 61: 1150-1156.

14. Menier C, Riteau B, Dausset J, Carosella ED, Rouas-Freiss N. HLA-G truncated isoforms can substitute for HLA-G1 in fetal survival. Hum Immunol 2000; 61: 1118-1125.

15. Castro MJ, Morales P, Rojo-Amigo R, Martínez-Laso J, Allende L, Varela, García-Berciano M, Guillen-Perales J, Arnaiz-Villena A. 2000. Homozygous HLA-G*0105N healthy individuals indicate that membrane - anchored HLA-G1 molecule is not necessary for survival. Tissue Antigens 2000; 56: 232-239.

16. Van der Ven K, Ober C. 1994. HLA-G polymorphisms in African Americans. J Immunol 1994; 153:5628-5633

17. Kirszenbaum M, Djoulam S, Hors J, Le Gal I, De Oliviera EB, Prost S, Dausset J, Carosella E.D. 1997. HLA-G gene polymorphism segregation within CEPH reference families. Hum Immunol. 53: 140-147.

18. Le Bouteiller P, Blaschitz A. The functionality of HLA-G is emerging. Immunol Rev 1999; 167: 233-244.

19. Pascale P, Cabestre AF, Ibrahim E, Lefebvre S, Khalil-Daher I, Vazeux G, Moya RM, Bermond F, Dausset J, Carosella ED. Identification of HLA-G mRNA and expression of soluble HLA-G5, -G6, and-G7 transcripts in human transfected cells. Hum Immunol 2000; 61: 1138-1149.

20. Kirszenbaum M, Moreau P, Gluckman E Dausset J, Carosella ED. An alternatively spliced form of HLA-G mRNA in human trophoblast and evidence for the presence of HLA-G transcrip in adult lymphocytes. Proc Natl Acad Sci USA 1994; 91: 4209-4213.

21. Ishitani A, Geraghty D. Alternative Splicing of HLA-G transcripts yields proteins with primary structures resembling both class I and class II antigens. Proc Natl Acad Sci USA 1992; 89: 3947-3951.

22. Fujii T, Ishitahi A, Geraghty DE. A soluble form of the HLA$G$ antigen is encoded by a messenger ribonucleic acid containing intron 4. J Immunol 1994; 153: 5516- 5524.

23. Rouas-Freiss N, Marchal RE, Kirszenbaum M, Dausset J, Carosella ED. 1997. The alpha 1 domain of HLA-G1 and HLA-G2 inhibits cytotoxicity induced by natural killer cells: is HLA-G the public ligand for natural killer cell inhibitory receptors. Proc Natl Acad Sci USA 1997; 94: 5249-5254.

24. Rebmann V, Pfeiffer K, Päbler M, Ferrone S, Mainer S, Weiss E, Grosse-Wilde. H. Detection of HLA-G molecules in plasma and amniotic fluid. Tissue Antigens 1999; 53:14-22.

25. Pascale P, Rouas-Freiss N, Khalil-Daher I, Moreau P, Riteau B, Le Gal A, Avril M, Dausset J, Guillet J, Carosella ED. HLA$\mathrm{G}$ expression in melanoma: A way for tumor cells to scape from immunosurveillance. Proc Natl Acad Sci USA 1998; 95: $4510-4515$. 
26. Lila N, Carpentier A, Amrein C, Khlil-Daher I, Dausset J, Carosella ED. Implication of HLA-G molecule in hearthgraff acceptance. Lancet 2000; 355: 2138.

27. Carosella ED, Rouas-Freiss N, Paul P, Dausset J. Cómo escapa el feto a las defensas de su madre. Mundo Científico 1998; 190: $24-26$

28. Le Bouteiller P, Solier C, Pröll J, Aguerre-Girr M, Fournel S, Lenfant F. Placental HLA-G protein expression in vivo: where and what for?. Hum Reprod Update 1999. 5: 223 -233.

29. Lanier L. Natural Killer cells fertile with receptors for HLAG?. Proc Natl Acad Sci USA. 1999; 96: 5343-5345.

30. Le Gal F, Riteau B, Sedlik C, Khalil-Daher I, Menier C, Dausset J, Guillet, J, Carosella ED, Rouas-Freiss N. HLA-G mediated inhibition of antigen-specific cytotoxic T lymphocytes. Int Immunol 1999 11:1351-1356.

31. Fournel S, Aguerre M, Huc X, Lenfant F, Alam A, Toubert A, Bensussan A, Le Bouteiller P. HLA-G1 triggers CD95/CD95 ligand-mediated apoptosis in activated CD8+ cells by interacting with CD8. J Immunol 2000; 164: 6100-6104.

32. Le Bouteiller P. HLA-G in the human placenta: expression and potential functions. Biochem Soc Trans 2000; 28: 208-212.

33. Carosella ED. HLA-G: Fetomaternal tolerance. CR Acad Sci III 2000; 323: 675-680.

34. Rabreau M, Rouas-Freiss N, Landi M, Le Danff C, Carosella ED. HLA-G expression in trophoblast cells is independent of embryonic development. Hum Immunol 2000; 61: 1108-1112.

35. O'Brien M, McCarthy T, Jenkins D, Paul P, Dausset J, Carosella E.D, Moreau P. Altered HLA-G transcription in pre-eclampsia is associated with allele specific inheritance: possible role of the HLA-G gene in susceptibility to the disease. Cell Mol Life Sci 2001; 58: 1943-1949.

36. O'Brien M, Dausset J, Carosella ED, Moreau P. Analysis of the role of HLA-G in preeclampsia. Hum Immunol 2000; 61: 1126-1131

37. Colbert GT, Chiang MH, Main EK. Expression of the nonclassical histocompatibility antigen HLA-G by preeclamptic placenta. Am J Obstet Gynecol 1994; 170(5): $1244-1250$.

38. Goldman-Wohl DS, Ariel I, Greenfield C, Mochner-Celnikier D, Cross J, Fisher S, Yagel S. Lack of human leukocyte antigen $\mathrm{G}-$ expression in extravillous trophoblast is associated with pre-eclampsia. Mol Hum Reprod 2000; 6: 88-95.

39. Karhupoki J, Laitinen T, Tiilikainen AS. HLA-G polymorphism in Finish couples with recurrent spontaneous miscarriage. Bris J Obstet Gynaecol 1997; 104:1212-1214.

40. Penzes M, Rajczy K, Gyodi E, Réti M, Fehér É, Petrányi G. 1999. HLA-G gene polymorphism in the normal population and in recurrent spontaneous abortion in Hungary. Transplant. Proc. 31: 1832-1833

41. Yamashita T, Fujii T, Tokunaga K. Analysis of human leukocyte antigen-G polymorphism including intron 4 in Japanese couples with habitual abortion. Am J Reprod Immunol 1999; 41:159-163.

42. Pfeiffer K, Fimmers R, Engels G, van der Ven H, van der Ven K. 2001. The HLA-G genotype is potentially associated with idiopathic recurrent spontaneous abortion. Mol Hum Reprod 2001; 7: 373-378.

43. Aldrich CL, Stephenson MD, Karrison T, Odem RR, Branch DW, Scott JR, Schreiber JR, Ober C. HLA genotypes and pregnancy outcome in couples with unexplained recurrent miscarriage. Mol Hum Reprod 2001; 7: 1167-1172.

44. Pascale P, Cabestré FA, Le Gal F, Khalil-Daher I, Le Danff C, Schmid M, Mercier S, Avril MF, Dausset J, Guillet J, Carosella E.D. Heterogeneity of HLA-G gene transcription and protein expression in malignant melanoma biopsies. Cancer Res 1999; 59: 1954-1960.

45. Onno M, Pangault C, Gaëlle LF, Guilloux V, Andre P, Fauchet R. Modulation of HLA-G antigens expression by human cytomegalovirus: specific induction in activated macrophages harboring human cytomegalovirus infection. J Immunol 2000. 164: 6426-6434.

46. Puppo F, Contini P, Ghio M, Indiveri F. Soluble HLA class I molecules/CD8 ligation trigger apoptosis of CD8+ cells by Fas/Fas-ligand interaction. Scientific World Journal 2002; 12: $2: 421-3$

47. Hofmeister V, Weiss EH. 2003. HLA-G modulates immune responses by diverse receptor interactions. Semin Cancer Biol 2003; 13(5):317-23.

48. Hunt J, Vassmer D, Ferguson T, Miller L. Fas Ligand is positioned in mouse uterus and placenta to prevent trafficking of activated leukocytes between the mother and conceptus. J Immunol. 1997 158:4122-4128. 